\title{
PRELIMINARY PHYTOCHEMICAL SCREENING AND ANTIMICROBIAL ACTIVITY OF ETHANOLIC EXTRACT OF STEMS OF IPOMOEA AQUATICA FORSK. (FAMILY-CONVOLVULACEAE)
}

\author{
IMDADUL HAQUE CHAUDHURY ${ }^{*}$, TRISHNA DAS ${ }^{2}$, DIPANKAR SAHA ${ }^{3}$ \\ ${ }^{1}$ Girijananda Chowdhury Institute of Pharmaceutical Science, Azara, Hatkhowapara, Guwahati-17, 2,3Depertment of Pharmacognosy, \\ Girijananda Chowdhury Institute of Pharmaceutical Science, Azara, Hatkhowapara, Guwahati-17 \\ Email: imdadbeing007@gmail.com
}

Received: 28 Jan 2017, Revised and Accepted: 20 Apr 2017

\begin{abstract}
Objective: To evaluate the antimicrobial activity ethanolic extracts of stems of the plant Ipomoea aquatica Forsk. (family-Convolvulaceae) along with preliminary phytochemical analysis.
\end{abstract}

Methods: The ethanolic extract of stems of the plant Ipomoea aquatica Forsk. (family-Convolvulaceae) were prepared and analyzed for phytochemical constituents using standard methods. The antimicrobial activity of the plant extracts was examined against 2 bacterial strains among one is gram positive and other is gram negative and 2 fungus using agar well diffusion method.

Results: The present experiment shows the phytochemical analysis, antimicrobial activity of the ethanolic extract of stems of the plant Ipomoea aquatic Forsk. (Family-Convolvulaceae). Various phytochemical analysis revealed the presence of alkaloids, saponin, flavonoids, carbohydrates, glycosides, Steroids, proteins and amino acids and tannins. All the extracts of the plant showed antimicrobial activity against most of the test organisms.

Conclusion: The present study concluded that ethanolic extract of stems of the plant Ipomoea aquatica Forsk. Contain the high presence of phytochemical. The ethanolic extract of the plant was found to possess promising antimicrobial activity when compared with the standards.

Keywords: Ipomoea aquatic Forsk., Antimicrobial, Zone of Inhibition, Agar disc diffusion method

(C) 2017 The Authors. Published by Innovare Academic Sciences Pvt Ltd. This is an open access article under the CC BY license (http://creativecommons.org/licenses/by/4.0/) DOI: http://dx.doi.org/10.22159/ijcpr.2017v9i4.20971

\section{INTRODUCTION}

Knowledge of herbs has been handed down from generation to generation for thousands of years. The revival of interest in natural drugs started in last decade mainly because of the widespread belief that green medicine is healthier than synthetic products. In the recent past, there has been a tremendous increase in the use of plant-based health products in developing as well as developed countries resulting in an exponential growth of herbal products globally. According to WHO, about $80 \%$ of the population in the world relay on the traditional medicine for the treatment of various diseases [1].

In the present era of drug development and discovery of newer drug molecules, many plant products are evaluated on the basis of their traditional uses. In this regard, one of the many plants which are being evaluated for their therapeutic efficacies is Ipomoeaaquatica (I. aquatica) (Convolvulaceae) which is a perennial herb found throughout India, Ceylon, Tropical Asia, Africa, and Australia [2].

This plant is grown as an aquatic plant which grows abundantly in marshy areas. Various parts of the I. aquatica plant are used medicinally in Southeastern Asia and reported to be useful for the treatment of high blood pressure, as an emetic in the treatment of opium and arsenic poisoning [3]. The dried juice has reported to be a purgative, while the leaves and stems possess cooling action. Moreover, it is also traditionally used in the treatment of nervous and general debility, piles, worm infections, leucoderma, leprosy, jaundice and liver complaints [4].

Very few studies have been done in this plant. This includes the inhibition of prostaglandin synthesis, eye diseases, constipation and hypoglycemic effects [5]. Phytochemical investigations of this plant have revealed the presence of carotenes such as $\beta$-carotene, cryptoxanthin, lutein, lutein epoxide, violoxanthin and neoxanthin, flavonoids such as mycertin, quercetin, luteolin and apigenin and some alkaloids [6].
In the Indian system of traditional medicine (Ayurveda) it is recommended to consume $I$. aquatica to mitigate disorders like jaundice. The effectiveness of these plant products from traditional claims must be proved to help develop novel drugs acting against these disorders. Nevertheless, no literature was found on the hepato-protective action of this plant. Keeping this in view, the present study was aimed to evaluate the hepato-protective activity of I. aquatica on Thioacetamide-induced liver damage in rats [7].

Medicinal plants have been tested for various kinds of activities such as antimicrobial, hypoglycemic, antihelmintic, hepatoprotective, antioxidant, analgesic, antipyretic activities. Antipyretic, antileishmanial and insecticidal activities. Medicinal plants such as Ocinumgratissimum and Eugenia uniflora are rich in volatile oils. It is also reported that they contain $75 \%$ thymol which has an antimicrobial effect against Staphylococcus sp., Escherichia coli and Shigella sp. They are also used in the treatments like diarrhea human ear infection [8].

Herbal medicines also offer therapeutics for age-related disorders like memory loss, osteoporosis, immune disorders, etc. for which no modern medicine is available. The chemical constituents present in them are a part of the physiological functions of living flora and hence they are believed to have better compatibility with the human body [9].

The therapeutic plants continually collaborate with the quickly changing and possibly harming outside ecological variables. In spite of the fact that living beings without versatility, plants have advanced expand elective safeguard methodologies, which include a huge assortment of compound metabolites as devices to conquer stretch conditions. The capacity of plants to complete combinatorial chemistry by mixing, coordinating and developing the quality items required for secondary metabolite biosynthetic pathways, makes a boundless pool of chemicals, which people have abused to their advantage. Consequently, the utilization of plants by people in both conventional and present day therapeutic frameworks, in this manner, to a great extent utilize this standard [10]. 
Ipomoea aquatica Forsk, commonly called water spinach, belongs to the family Convolvulaceae is a perennial herb and tender, trailing or floating perennial aquatic plant found on moist soil along the margins of fresh water. It is also commonly used as a green leafy vegetable in rural India Studies with Ipomoea aquatica Forsk revealed that the inhibition of prostaglandin synthesis, effects on liver disease and constipation [11].

So the point of this present study is to recognize the phytochemical of Ipomoea aquatica Forsk. and to decide the antimicrobial effects of the stem extract on E. coli, S. aureus, Candida albicans and Trichophyton rubrum.

\section{MATERIALS AND METHODS}

\section{Collection of plant materials}

Ipomoea aquatica Forsk. was collected from Azara of Kamrup district of Assam in October 2016 and the plant was thoroughly washed with water; roots and leaves were discarded and the stems were dried in shade for $2 \mathrm{w}$ and finally dried in a thermostatic oven at a considerably low temperature not exceeding $30{ }^{\circ} \mathrm{C}$ for $24 \mathrm{~h}$. The plant was authenticated by Prof. Dr. G. C. Sharma, Department of Botany, Gauhati University. A voucher specimen (Acc. No.18210, Dated: 28.10.2016) was kept in Department of Botany, Gauhati University for future reference.

\section{Chemicals and reagents}

Ethanol (ET), Petroleum Ether(PE),dimethyl sulfoxide (DMSO), hydrochloric acid, Dragondorff reagent, Mayer's reagent, Wagner's reagent, Benedict's reagent, sulphuric acid, lead acetate, Molisch's reagent, Fehling solution A and B, sodium citrate, copper sulphate, ferric chloride, sodium hydroxide, glacial acetic acid, benzene, chloroform, ammonia, nitric acid, dimethyl sulfoxide (DMSO), potassium nitrite, gelatine, Beef extract, Peptone and agar. All the chemicals and solvents used were of standard analytical grades.

\section{Preparation of plant extracts}

I. aquatica was carried out using ethanol (99.5\%) by maceration method at room temperature. $100 \mathrm{gm}$ of the ground sample was taken in the round bottom flask. To that above flask, $500 \mathrm{ml}$ of ethanol was poured and was kept aside under cold maceration technique for about $7 \mathrm{~d}$ with intermittent shaking. The liquid extract was then distilled off and the remaining solvent was allowed to evaporate in a water bath at a constant temperature. Then it was poured in a tarred Petri dish was dried for several days. The concentrated extract was then weighed and the percentage yield was calculated and finally stored in airtight container at $4{ }^{\circ} \mathrm{C}$. Thus total ethanolic extract is obtained which was used for investigation. The percent yield of ethanolic extract was then calculated out.

\section{Preparation of extract/drug stock solution}

The stock solution oflpomoea aquatica stem extract was prepared on each occasion by careful weighing and dissolving in a suitable volume of Dimethylsulphoxide (DMSO) to get a concentration of 100 $\mathrm{mg} / \mathrm{ml}$. A tablet of ciprofloxacin was dissolved in an appropriate volume of water to get $5 \mathrm{mg} / \mathrm{ml}$ of stock solution.

\section{Phytochemical screening}

The Ethanolic extract of Ipomoea aquatica was subjected to preliminary phytochemical screening for their presence or absence of active constituents utilizing a standard method of analysis.

\section{Test for alkaloids}

Extracts were dissolved individually in dilute Hydrochloric acid and filtered. The filtrate was carefully tested with various alkaloidal reagents as follows:

(a) Dragondroff's Test: To the filtrates, few drops of dilute Dragondroff's reagent (Potassium bismuth iodide solution) was added. An orange-brown precipitate indicates the presence of alkaloids. (b) Wagner's Test: To the filtrates few drops of Wagner's reagent (Iodine-potassium iodide solution) was added. Reddish brown precipitate indicates the presence of alkaloids.

(c) Mayer's Test: To the filtrates few drops of Mayer's Reagent (Potassium mercuric iodide solution) was added. Cream precipitate indicates presence of alkaloids.

\section{Test for saponins}

Foam Test: $0.5 \mathrm{gm}$ of extract was shaken with $2 \mathrm{ml}$ of water. If foam produced persists for ten minutes it indicates the presence of saponins.

\section{Test for flavonoids}

The ethanol extract $5 \mathrm{ml}$ was added to a concentrated sulphuric acid (H2SO4) $(1 \mathrm{ml})$ and $0.5 \mathrm{~g}$ of $\mathrm{Mg}$. A pink or red coloration that disappear on standing $3 \mathrm{~min}$. indicates the presence of flavonoids.

\section{Test for tannins}

Gelatin Test: To the extract, 1\% gelatin solution containing sodium chloride was added. Formation of white precipitate indicates the presence of tannins

\section{Test for carbohydrates}

Extract was dissolved individually in $5 \mathrm{ml}$ distilled water and filtered. The filtrates were used to test for the presence of carbohydrates.

a) Molisch's Test: Filtrates were treated with 2 drops of alcoholic $\alpha$ naphthol solution in a test tube. Formation of the violet ring at the junction indicates the presence of Carbohydrates.

b) Benedict's Test: Filtrates were treated with Benedict's reagent and heated gently. Orange red precipitate indicates the presence of reducing sugars.

c) Fehling's Test: Filtrates were hydrolysed with dil. HCl, neutralized with alkali and heated with Fehling's A and B solutions. Formation of red precipitate indicates presence of reducing sugars.

\section{Test for glycoside}

$2 \mathrm{ml}$ of concentrated $\mathrm{H} 2 \mathrm{SO} 4$ was added carefully and shaken gently. A reddish brown colour indicated the presence of steroidal ring i. eglycone portion of the glycoside.

\section{Test for phytosterols}

Salkowski's Test: Extract was treated with chloroform and filtered. The filtrates were treated with few drops of Conc. Sulphuric acid, shaken and allowed to stand. Appearance of golden yellow colour indicates the presence of triterpene.

\section{Test for proteins and amino acids}

Xanthoproteic Test: The Extract was treated with few drops of conc. Nitric acid. Formation of yellow colour indicates the presence of proteins.

\section{Fluorescence analysis}

Table 2 represents the results of the fluorescence characteristics ofIpomoea aquatica Forsk. Powdered drug in day light, short UV light $(\lambda \max 254 \mathrm{~nm})$ and long UV light $(\lambda \max 365 \mathrm{~nm})$. The identification and comparison of the colors was done using the standard colour index chart.

\section{Microbial strains}

Three bacterial strains [Staphyllococcusaureus (ATCC 25923), Escherichia coli (ATCC 25922) and two fungi [Candida albicans (ATCC 10231), and Trichophytonrubrum (ATCC 28188)] were used. Stains were obtained from Girijananda Chowdhury Institute of Pharmaceutical Science, Azara, Guwahati.

\section{Sterilization of materials}

The petri dishes and pipettes packed into metal canisters were appropriately sterilized in the hot air oven at $170^{\circ} \mathrm{C}$ for $1 \mathrm{~h}$ at each 
occasion. A solution of the extract and culture media were autoclaved at $121^{\circ} \mathrm{C}$ for $15 \mathrm{~min}$.

\section{Culture media}

The media employed for the study was solid agar media.

\section{Antibacterial activity}

The antimicrobial activity of the different extracts of the plant was assayed by agar-well diffusion method as described in NCCLS, 1993 [12]. Petri plates containing $20 \mathrm{ml}$ nutrient agar medium was seeded with bacterial strains. Wells of approximately $10 \mathrm{~mm}$ was bored using a well cutter. Plant extracts were prepared in DMSO (stock: 1 $\mathrm{mg} / \mathrm{ml}$ DMSO). The plant extracts of 25, 50, and $100 \mu \mathrm{l}$ concentrations were added. Ciprofloxacin (20 $\mu \mathrm{l})$ and DMSO (100 $\mu \mathrm{l})$ were used as positive and negative controls respectively. The plates were then incubated at $37^{\circ} \mathrm{C}$ for $24 \mathrm{~h}$. The antimicrobials present in the plant extract are allowed to diffuse out into the medium and interact with the test organisms in the freshly seeded plate. The diameter of the zone of inhibitions was measured in millimeters after $24 \mathrm{~h}$.

\section{Antifungal activity}

The potato dextrose agar plates were prepared and inoculated with a fungal culture. Wells of approximately $10 \mathrm{~mm}$ was bored using a well cutter and samples of different concentration were added. The zone of inhibition was measured in millimeters after overnight incubation and compared with that of standard antifungal (Fluconazole) (10 $\mu \mathrm{l})$ which was used as positive control and DMSO (10\%) as the negative control [13].

\section{RESULTS}

The present investigation shows the phytochemical analysis, antimicrobial activity of the ethanolic extract of the plant Ipomoea aquatic Forsk. The yield \% of the extraction of ethanol was \%. It was a dark green solid powder (ET) in appearance.

\section{Phytochemical analysis}

Phytochemical investigations with the ethanolic plant extract have demonstrated the presence of alkaloids, saponin, flavonoids, glycosides, Steroids, carbohydrate, proteins and amino acids and tannins (table 1).

\section{Antimicrobial activity}

The Plant extract is generally rich in antimicrobial compounds. The in vitro antimicrobial activity of the ethanolic extract of Ipomoea aquatic Forsk. Under different concentration with the standard are appeared at table 3. The ethanolic extract of stems of the plant showed antimicrobial activity against a large portion of the test organisms.

Table 1: Phytochemical screening of Ethanolic (ET) extract of stems of Ipomoea aquatica Forsk

\begin{tabular}{llll}
\hline S. No. & Phytochemicaltest & Reagentsused (testperformed) & Observation \\
\hline 1 & Alkaloidstest & Mayer's test & Creamy white precipitate \\
& & Wagner's test & Reddish brown colour yellow precipitate \\
& & Dragendoroff's test & Orange brown precipitate \\
2 & Saponin test & Foam test & Froth formation \\
3 & Flavonoidstest & LeadAcetate test & Yellow precipitate \\
4 & Carbohydrate test & Molisch'stest & Formation of violetring \\
& & Benedict's test & Formation of orange redprecipitate \\
& & Fehling's test & Formation of redprecipitate \\
6 & Glycosides test & Modified Borntrager's test & Formation of pink colour \\
7 & Steroidtest & Salkowski's test & Formation of greencolour \\
8 & ProteinsandAmino Acids & Xanthoproteic test & Formation of yellowcolour \\
\hline
\end{tabular}

Note: +sign indicatespresenceand-sign indicatesabsence.

Table 2: Fluorescence analysis power drug of Ipomoea aquatica Forsk. Stems

\begin{tabular}{|c|c|c|c|c|}
\hline S. No. & Powder+reagent & Visible light & Short UV light (254 nm) & Long UV light (365 nm) \\
\hline 1 & Powder as such & Green & Green & Dark Green \\
\hline 2 & Powder $+1 \mathrm{~N} \mathrm{NaOH}$ in methanol & Light yellow & Leaf green & Dark green \\
\hline 3 & Powder+Conc. $\mathrm{HNO} 3$ & Light yellow & Light brown & Reddish brown \\
\hline 4 & Powder+Conc. $\mathrm{HCl}$ & Gold & Emerald & Blue \\
\hline 5 & Powder+Conc. H2SO4 & Dark green & Black & Black \\
\hline 6 & Powder+KOH (5\%) & Greenish yellow & Dark green & Blue \\
\hline 7 & Powder $+\mathrm{FeCl} 3(5 \%)$ & Yellowish Brown & Brown & Dark green \\
\hline 8 & Powder+Picric acid & Yellowish green & Green & Dark green \\
\hline
\end{tabular}

Table 3: Antimicrobial activity Ethanolic (ET) extract of stems of Ipomoea aquatica Forsk. using disc diffusion assay

\begin{tabular}{|c|c|c|c|c|}
\hline \multirow[t]{2}{*}{$\begin{array}{l}\text { Name of the compounds and their } \\
\text { concentration }\end{array}$} & \multicolumn{2}{|c|}{$\begin{array}{l}\text { Antibacterial activity diameter of inhibition } \\
\text { zone (mm) }\end{array}$} & \multicolumn{2}{|c|}{$\begin{array}{l}\text { Antifungal activity diameter of inhibition } \\
\text { zone ( } \mathrm{mm})\end{array}$} \\
\hline & Staphylococcus aureus & Escherichia coli & C. albicans & Trichophyton rubrum \\
\hline Standard Ciprofloxacin $(20 \mu \mathrm{l})$ & 44 & 42 & ---- & $\cdots$ \\
\hline Standard Fluconazole $(20 \mu \mathrm{l})$ & ----- & ----- & 31.30 & 30.10 \\
\hline Plant extract $(25 \mu l)$ & 13.2 & 11.3 & 11.90 & 10.10 \\
\hline Plant extract $(50 \mu l)$ & 17.53 & 14.92 & 16.70 & 12.55 \\
\hline Plant extract $(100 \mu l)^{*}$ & 22.64 & 18.20 & 20.04 & 15.12 \\
\hline
\end{tabular}

*significant activity 


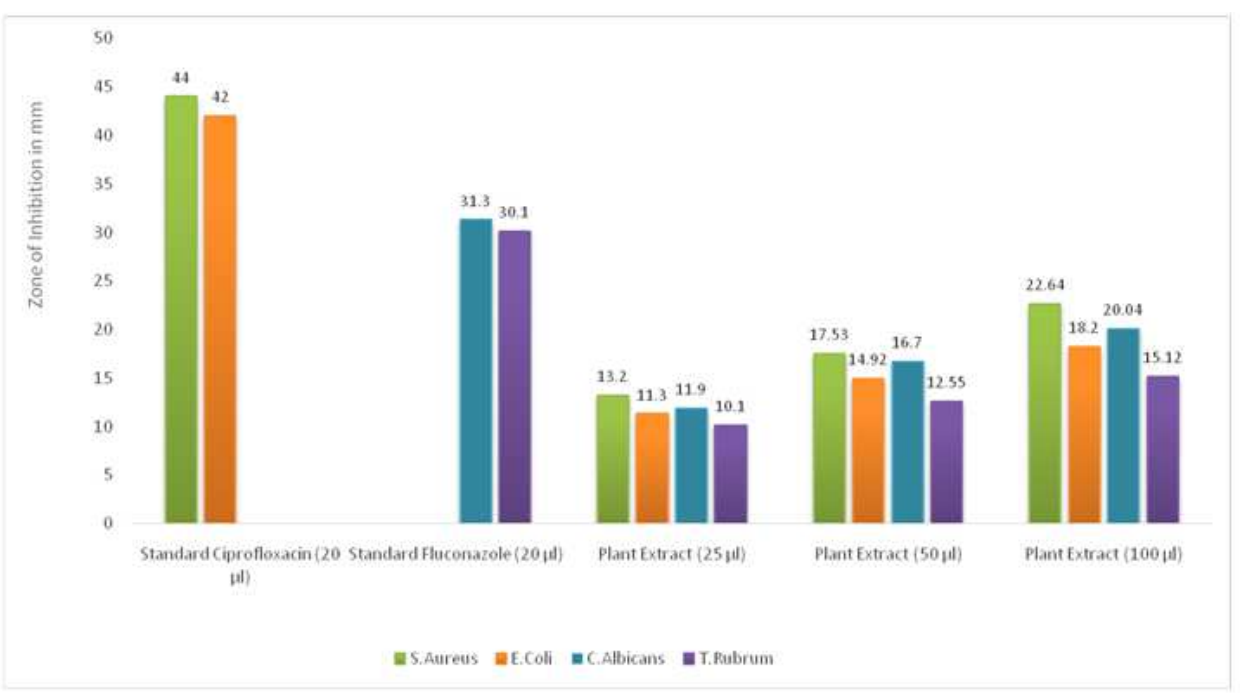

Fig. 1: Zone of inhibition vs concentration

\section{DISCUSSION}

The antimicrobial activity of Ipomoea aquatic Forsk. Has been evaluated. Phyto-constituents exhibit in plants to be specific alkaloids, flavonoids, tannins, and triterpenoids are delivering an energizing open door for expansion of modern therapies against extensive variety of microorganisms. The present study was done against the variety of Gram-positive, Gram-negative bacteria, and fungal strains were selected for screening antimicrobial impact of the extracts to see the antimicrobial spectrum. The consequences of this study shows that the ethanolic extracts of the plant Ipomoea aquatic Forsk. Were highly successful in producing the desired result against most of the Gram-positive bacteria, Gram-negative bacteria, and fungal strains in agar well diffusion method.

Phytochemical constituents of plants such as tannins, alkaloids, flavonoids, phenolic compounds and several other aromatic compounds are secondary metabolites of plant that fill in as a barrier component against predation by numerous microorganisms.

The exhibition and explanation of antimicrobial activity against both Gram-positive and Gram-negative bacteria and on various fungal strains may be an indication of something presence of broad spectrum antibiotic compounds in the extracts which is shown in fig. 1. The $100 \mu \mathrm{g} / \mathrm{ml}$ concentration of extract having the most affecting antimicrobial activity.

\section{CONCLUSION}

The results obtained from this work showed that plant extracts of Ipomoea aquatica Forsk. Exhibit antimicrobial effects. In the concluding part, the future scope of Ipomoea species has been emphasized with a view to establish their biological activities and mode of action. Therefore, it is absolutely necessary to evaluate the antimicrobial activity of Ipomoea aquatica Forsk.

During the study, the antibacterial activity of the stems of Ipomoea aquatica Forsk. was judged by using disk diffusion method. The microorganisms that have been selected for study were Gram positive, $S$. aureus and Gram-negative $E$. coli and fungus like $C$. albicans, and T. rubrum. Study of this micro-organism were done as they are important pathogens and also they have the capacity of rapidly developed antibiotic resistance as antibiotic use increases.

At the end the study concluded that ethanolic extract of Ipomoea aquatica Forsk. showed the presence of various phytochemicals of which include alkaloids, saponin, carbohydrate, Steroids, and terpeniods.

The present study makes us know about the significant antimicrobial activity of the plant extracts when estimated with standards. So, after lots test, decision and thoughts it was found that the minimum inhibitory concentration of the plant extracts was less than $100 \mu \mathrm{g} / \mathrm{ml}$ and therefore the plant was considered to have a very good antimicrobial activity.

Further studies are needed to determine the chemical identity of the bioactive compounds responsible for the observed antimicrobial activity and unknown biological activities of Ipomoea aquatic Forsk. and its effect on living organisms, tissues or cells against various diseases.

\section{ACKNOWLEDGMENT}

The authors acknowledged the Head of Department, Guwahati university for authenticating the plant and Principal and Department of Microbiology, Girijananda Chowdhury Institute of Pharmaceutical Science, Azara, Guwahati for conveying this exploration work.

\section{CONFLICT OF INTERESTS}

Declare none

\section{REFERENCES}

1. Padmaa MP, Leena JP, Angelin ST. Genius salacia: a comprehensive review. J Nat Remedies 2010;8:116-31.

2. Nadkarni KM. Ipomoea aquatica Forsk. Indian Materia Medica. Vol. I. Mumbai: Popular Prakashan; 1954. p. 684-5.

3. Perry LM. Medicinal plants of East and Southeast Asia: attributed properties and uses; The MIT Press: Cambridge, MA USA; 1980.

4. Chopra RN, Nayar SL, Chopra IC. Glossary of Indian medicinal plants; council of scientific and industrial research (CSIR): New Delhi, India; 1956.

5. Tee E, Lim CL. Carotenoid composition and content of Malaysian vegetables and fruits by the AOAC and HPLC methods. Food Chem 1991;41:309-39.

6. Tofern B, Mann P, Kaloga M, Jenett-Siems K, Witte L, Eich E. Aliphatic pyrrolidine amides from two tropical convolvulaceae species. Phytochemistry 1999;52:1437-41.

7. Prasad KN, Shivamurthy GR, Aradhya ZSM. Ipomoea aquatica, an underutilized green a leafy vegetable: a review. Int J Bot 2008;4:123-9.

8. Fadeyi MO, UE Alcapan W. Preliminary phytochemical analysis and antimicrobial activity ethanolic extracts of dried fruits of solanum torvum (Family-solanaceae). West Afr J Pharmacol Drug Res 1989;9:29-30.

9. Vickers A, Zollman C. ABC of complementary medicine: herbal medicine. Br Med J 1999;319:1050-3.

10. Ncube B, Finnie JF, Staden JV. In vitro antimicrobial synergism within plant extract combinations from three South African medicinal bulbs. J Ethnopharmacol 2012;139:81-9. 
11. Chen J, Hoch P, Raven PH. Flora of China. Vol. 13. Epilobium; 2011. Available from: http://www.efloras.org/ flora_page. aspx?flora id=2. [Last accessed on 18 Dec 2016]

12. National Committee for Clinical Laboratory Standards. Performance Standards for Antimicrobial Disk Susceptibility Tests-Fifth Edition: Approved Standard M2-A5. NCCLS Villanova PA; 1993a.

13. Kurian S, Josekumar VS. Phytochemical screening, antimicrobial activity and brine shrimp lethality bioassay of different extracts of alysicarpusvaginalisvar. nummular folious (DC.) MIQ. (family: fabaceae). Int J Pharm Sci 2017;9:1-6.

\section{How to cite this article}

- Imdadul Haque Chaudhury, Trishna Das, Dipankar Saha Preliminary phytochemical screening and antimicrobial activity of ethanolic extract of stems of Ipomoea aquatica forsk. (familyconvolvulaceae). Int J Curr Pharm Res 2017;9(4):109-113. 